\title{
Toxic Methemoglobinemia with Cyanosis
}

National Cancer Institute

\section{Source}

National Cancer Institute. Toxic Methemoglobinemia with Cyanosis. NCI Thesaurus.

Code C110936.

Blue skin coloration due to elevated blood levels of methemoglobin. The degree of cyanosis is directly correlated to the concentration of methemoglobin in the blood. As methemoglobin is not suitable for carrying oxygen, hypoxemia becomes a serious sequela. 